\title{
A diversidade religiosa e a laicidade no Brasil: questões sobre o ensino religioso escolar
}

\author{
Religious diversity and laity in Brazil: questions about religious education in \\ schools
}

Nathália Ferreira de Sousa Martins - UFJF*

nathsousa_martins@hotmail.com

\begin{abstract}
Resumo: Desde 1997 a Lei de Diretrizes e Bases da Educação Nacional garante a disciplina de Ensino Religioso (ER) no formato não proselitista, respeitando a diversidade cultural religiosa do país. Entretanto por conta do histórico de um ER catequético no Brasil, alguns autores militam contra a disciplina, defendendo a "laicidade" do Estado. No entanto, há pesquisadores e educadores que defendem o ER, tendo como base a Ciência da Religião, onde se trabalha o fenômeno religioso de uma forma holística, não confessional, e não proselitista, compreendendo a religião como um fenômeno cultural, histórico, parte integrante da sociedade brasileira. Nesse sentido, não haveria problema em o Estado subvencionar esse ensino, pois não fere a laicidade estatal. Sendo assim esse artigo busca compreender a relação entre a maneira como o estado brasileiro foi constituído, o tipo de laicidade que aqui se exerce e a importância de um ER que resguarde a laicidade do estado e garanta aos discentes, acesso à diversidade de seu patrimônio cultural-religioso.
\end{abstract}

Palavras-Chave: Ensino Religioso. Laicidade. Diversidade.

Abstract: Since 1997 the Law of Guidelines and Bases of National Education guarantees the discipline of Religious Education (RE) in non-proselytizing format, respecting the religious cultural diversity of the country. However, because of the history of a catechetical RE in Brazil, some authors militate against discipline, defending the "laicity" of the State. However, there are researchers and educators who defend the RE, based on the Science of Religion, where the religious phenomenon is worked in a holistic, non-confessional, and nonproselytizing way, understanding religion as a cultural phenomenon, historical, integral part of Brazilian society. In this sense, it would not be a problem for the State to subsidize this teaching, since it does not harm state laicity. Thus, this article seeks to understand the relationship between the way the Brazilian state was constituted, the type of laicity exercised here and the importance of an RE that preserves the laity of the state and guarantees the students access to the diversity of their cultural religious-heritage.

Keywords: Religious Education. Laicity. Diversity.

\footnotetext{
Mestranda do Programa de Pós-graduação em Ciência da Religião da Universidade Federal de Juiz de Fora Bolsista da CAPES, especialista em Ensino Religioso pela Faculdade Unida de Vitória, licenciada em Filosofia pela faculdade SINAL e Bacharel em Teologia pela Faculdade Unida de Vitória.
} 


\section{Introdução}

De acordo com uma pesquisa realizada em 65 países pela rede Worldwide Independent Network of Market Research (WIN), em 2015, no Brasil, 79\% da população declaram seguir uma religião, isto é 8 em cada 10 brasileiros $^{1}$. No censo de 2010 o IBGE identificou mais de 40 expressões religiosas ${ }^{2}$. Esses dados reforçam que na sociedade brasileira há uma grande diversidade religiosa, sem contar aqueles que se denominam ateus, agnósticos ou sem religião. De acordo com Brandão (1994, p.10 apud MOTA, 2015, p.74) a educação se apresenta como "uma fração do modo de vida dos grupos sociais que a criam e recriam, entre tantas outras invenções se sua cultura, em sua sociedade”, nesse sentido, na escola, toda essa realidade religiosa presente na sociedade, os conflitos, os diálogos, se refletem, e como lidar com eles? Há espaço para se pensar sobre religião nas escolas públicas?

A disciplina de Ensino Religioso é uma realidade no Brasil desde os tempos do Império, porém com uma característica de catequese, proselitista (MOTA, 2015, p.79). Entretanto, esse modelo não é adequado para essa sociedade plural e diversa, uma vez de que fere a laicidade do Estado. Desde 1997 com a redação do artigo 33 da Lei de Diretrizes e Bases da Educação Nacional (LBD), esforços de educadores e pesquisadores vem sendo feitos para a efetivação de um outro modelo de ER que seja não proselitista, não confessional, que resguarde a diversidade cultural religiosa do Brasil e que, desse modo, não interfira na laicidade estatal.

Para entender as discussões que envolvem o Ensino Religioso nas escolas, há que se voltar os olhos para o desenvolvimento da secularização e laicização no país e compreender o processo histórico de constituição do estado brasileiro onde a religião esteve sempre presente desempenhando papel importante.

\section{Processo de Secularização e Laicidade à Brasileira}

\footnotetext{
${ }^{1}$ Disponível em: < http://www.ibope.com.br/pt-br/noticias/Paginas/Oito-em-cada-dez-brasileiros-se-consideramreligiosos.aspx>. Acesso em 28/08/2017.

2 Disponível em:

<http://biblioteca.ibge.gov.br/visualizacao/periodicos/94/cd_2010_religiao_deficiencia.pdf>. Acesso em: 28/08/2017.
} 
Processo de Secularização é um conceito que começou a ser utilizado no século XIX. Muitos autores remontam sua origem a Max Weber, e no decorrer dos anos foi agregado a esse conceito uma multiplicidade de sentidos. De acordo com Pierucci, Max Weber denomina o processo de secularização como o "desenvolvimento da sociabilidade e de modos de sociação característicos das modernas sociedades euro-norte-americanas de matriz puritana forte”; parte do processo societário de diferenciação de esferas culturais -institucionais” (PIERUCCI, 1998, p.5). Weber observou de forma histórica o "campo das transformações objetivas que afetam religião e seu estatuto cultural e, simultaneamente, aos processos de racionalização das diferentes esferas culturais de valor e dos modos de levar a vida" (PIERUCCI, 1998, p.6).

De acordo com as análises de Pierucci, Weber faz a constatação da mudança pela via da comparação de dois momentos da história do Ocidente: o século XVII (época religiosa), e o seu próprio tempo o século XX na Alemanha (secularizada) onde se podia experimentar o desencantamento do mundo. Weber tratou a secularização do estado como um dado da modernidade, como algo que estava acontecendo e não que iria acontecer. Pierucci observa que “os conteúdos temáticos da obra de Weber estão perpassados por este 'motiv' dos dois tempos”: (1) tempo da religiosidade, no qual o “Além era tudo” para os seres humanos; e (2) o tempo de "agora” do Weber, o século XX. O autor considera que esse tempo, de agora, também é o nosso, dos cientistas que são os “utilitários herdeiros” da época da religiosidade do século XVII (PIERUCCI, 1998, p.7)

Atrelado ao Processo de Secularização há outro processo, o de Desencantamento do Mundo, também pensado por Max Weber, porém os processos são diferentes. Sobre o desencantamento, Pierucci argumenta que Weber se inspirou no termo des-divinização ou des-endeusamento usado pelo poeta Schiller. O desencantamento é usado por Weber para designar o longo período de racionalização que a religiosidade ocidental passou devido a "hegemonia cultural alcançada por essa forma "eticizada” da religião desencantadora desse mundo: o judeo-cristianismo". O ponto de partida para o processo de desencantamento foram os profetas de Israel e o ponto de chegada foram as seitas puritanas, e depois transitou até a “primazia da ciência moderna” (PIERUCCI, 1998, p. 8)

Para muitos autores secularização e desencantamento do mundo são equivalentes, entretanto, o Pierucci mostra a diferença entre esses dois conceitos, a partir da diferenciação sutil que Weber faz. Desencantamento é um processo religioso, ocorre em sociedades 
religiosas; as religiões éticas operam a eliminação da magia como meio de salvação, ou seja, desencantamento religioso do mundo é a eliminação da magia como meio de salvação. Já secularização implica um abandono, redução, subtração da religião e emancipação em relação a ela. Esta é uma consequência, observada por Weber, do processo de desencantamento do mundo (PIERUCCI, 1998, p.8).

Ambos os processos se encontram no processo de modernização, onde o efeito sobre a religião é negativo, já que segundo Pierucci, "consolida e faz avançar o desencantamento do mundo através de uma crescente racionalização da dominação política que é irresistivelmente laicizadora”. Dessa forma tornou-se comum embaralhar os dois conceitos e considerar Weber o autor da teoria da secularização, ou tese da secularização como alguns autores preferem (PIERUCCI, 1998, p.9).

A partir do século XIX há uma expansão semântica do termo, num contexto 'avançadamente' secularizado, onde o conceito se torna uma categoria histórico-filosófica que pretende interpretar a história universal a partir da modernidade ocidental. É nesse contexto que nascem as grandes críticas ao processo de secularização. Para muitos autores, Weber decretou o fim da religião, pois com a avanço da modernidade haveria um retraimento da religião. Porém com o passar dos anos, com o advento das duas grandes guerras, a modernidade foi questionada. E acontece então a volta da religião ou como se costuma dizer, o 'revival' religioso, que se caracteriza pelo aumento significativo de novas religiões e novas tradições. A partir disso, muitos autores como Barbano, Berger, Martelli, Crespi, Tschannen, Negrão, Sanchis, argumentaram que o mundo estaria passando por uma dessecularização.

Pierucci explica que dessecular, pós-secular se alinham com os outros "pós" (pósmoderno, pós-materialista, pós-comunista ...). Ele remonta o termo aos anos de 1990 onde o autor Fillipo Barbano usou pós-secular pela primeira vez, este identifica na pós-modernidade uma crise globalizada da modernidade e, "o momento ideal para a reformulação das teorias sociológicas da religião, uma vez que elas seriam majoritariamente tributárias do doutrinarismo da teoria weberiana da secularização”, assim reconhecendo a capacidade da religião em resistir aos ataques da modernidade. Seria uma reformulação da sociologia da religião, tratando esse objeto de uma forma menos injusta e menos preconceituosa, diferindo da modernidade (PIERUCCI, 1998, p.2). 
Para Pierucci, essa condição pós-moderna propicia aos sociólogos da religião um abandono da modernidade e também uma ruptura com Weber, pois em sua sociologia constatou o "retraimento da religião na razão direta do avanço da modernização capitalista”. Alguns autores associam a expansão da religião, o 'revival' religioso, como um fenômeno de dessecularização, este, não sendo só perceptível no Terceiro Mundo, mas também no Primeiro Mundo. Pierucci continua a sua crítica dizendo, que essa volta da religião "é um dos grandes fatos sociais da contemporaneidade a sancionar precisamente o "pós” da pós-modernidade”. O crescimento da área da sociologia da religião também é identificado como fenômeno da dessecularização, e juntamente a esse fator está a emergência dos Novos Movimentos Religiosos, cujo impacto midiático atingiu o pico na década de 80, povoando o cotidiano das abastadas classes médias do Primeiro Mundo com deuses novos e velhos. Outras evidências desse fenômeno seriam: a recuperação da imagem do papado, o impacto televisivo dos evangélicos fundamentalistas ou tradicionais e o fundamentalismo islâmico com suas repúblicas teocráticas. Não seria então o fim da religião, seria uma volta "projetando nessa volta uma reviravolta anti-iluminista, algo como o “fim da secularização” (PIERUCCI, 1998, p.3)

Todo esse movimento foi chamado por alguns como uma “revanche de Deus”, que só surpreenderia aqueles que tem por ideologia prognósticos racionalistas, positivistas, incluindo os fundadores da sociologia que pretendiam o “fim histórico do sagrado”. Pierucci salienta que vários autores ligados à teoria da dessecularização consideram que Weber fora superado, pois suas análises foram válidas para um período encerrado na história do ocidente: a modernidade, onde o sagrado se exilou. Entretanto nesse novo período de reencantamento, o sagrado persistiu, paralelamente ao reencantamento primeiro-mundista (Negrão, 1994). Seguindo esse raciocínio no Brasil nem teria acontecido o desencantamento do mundo (PIERUCCI, 1998, p.4).

Todavia, Pierucci, argumenta que esses autores, fazem uma leitura rala e tola, que não combina com Weber, pois este "sempre foi metateoricamente avesso a previsões fechadas com pretensão nomológica no formato teleológico-hegeliano do gênero filosofia da história. Como, então, atribuir-lhe a tese do “fim histórico da religião”? Como falar em profecia weberiana não cumprida?” (PIERUCCI, 1998, p. 5)

Atrelado a essas críticas está Talal Asad, como parte de seus argumentos diz que o processo de secularização, retraimento da religião, só aconteceu na Europa, no mundo 
ocidental, uma vez que nas américas e no Oriente Médio, esse processo aconteceu de forma diferente com a religião sempre presente. Sendo assim, não se poderia dizer que esse processo é universal (ASAD, 2003). Para isso seria importante analisar o processo de constituição de cada país e verificar como esse processo ocorreu, quais são suas características e como é a relação da religião com o estado nesses país. Antes de especificar o caso do Brasil, vale fazer uma diferenciação entre o Processo de Secularização e a Laicidade.

De acordo com Ricardo Mariano, laicidade,

recobre especificamente à regulação política, jurídica e institucional das relações entre religião e política, igreja e Estado em contextos pluralistas. Refere-se, histórica e normativamente, à emancipação do Estado e do ensino público dos poderes eclesiásticos e de toda referência e legitimação religiosa, à neutralidade confessional das instituições políticas e estatais, à autonomia dos poderes político e religioso, à neutralidade do Estado em matéria religiosa (ou a concessão de tratamento estatal isonômico às diferentes agremiações religiosas), à tolerância religiosa e às liberdades de consciência, de religião (incluindo a de escolher não ter religião) e de culto. (MARIANO, 2011, p.244)

O termo secularização não se recobre totalmente ao de laicidade. Para Oro enquanto a secularização representa a ideia de exclusão do espaço público, laicidade "designa a maneira pela qual o Estado se emancipa da referência religiosa”. Ambos os conceitos, secularização e laicidade “compartilham a noção de autonomização das esferas sociais, sobretudo do político em relação à religião, e ambos não se confundem com ateísmo” (ORO, 2011, p.224.)

Há uma delimitação conceitual mais precisa do termo laicidade. O conceito de secularização quando se refere ao processe de secularização do Estado, do ensino, da política, da esfera jurídica, nada perde em precisão em relação ao de laicidade, conforme Mariano (MARIANO, 2011, p.245). Na continuidade do texto dar-se- a preferência ao termo laicidade, pois nas discussões sobre o ER o termo laicidade está mais presente.

Os processos de secularização e laicização dos estados, são distintos de país para país, uma vez que cada um têm suas características históricas que modelaram esses processos. Para Oro (ORO, 2011, p. 222) laicidade e a separação entre política e religião são características do mundo ocidental, e não ocorrem de forma homogênea nesses países. O autor enxerga três modelos de laicidade, há aqueles países que “mantém um regime de separação Estado-Igreja; outros que adotam o regime de separação Igrejas e Estado com dispositivos particulares em relação a algumas religiões ou igrejas; e países que adotam o regime de Igrejas de Estado” (ORO, 2011, p. 222). Para ele o modelo que vigora no Brasil é o de separação Estado-Igreja, 
onde não há o comprometimento do Estado com certas igrejas e religiões e, predomina “os princípios da liberdade religiosa e de cultos, da não discriminação religiosa por parte do Estado e da separação entre poder político e poder religioso”. Oro caracteriza a laicidade brasileira como "laicidade aberta, a qual defende a 'distinção' entre o poder temporal e o espiritual, e a ‘separação’ entre Igreja e Estado, assegurando à religião um lugar na sociedade e não a sua eliminação” (TERNISIEN, 2007, p. 26 apud ORO, 2011, p. 224).

O marco da laicidade no Brasil foi, segundo Giumbelli, a aurora republicana, quando se adota o princípio da separação entre Estado e igrejas,

Em termos mais concretos: rompe-se com o arranjo que oficializava e mantinha a Igreja Católica; o ensino é declarado leigo, os registros civis deixam de ser eclesiásticos, o casamento torna-se civil, os cemitérios são secularizados; ao mesmo tempo, incorporam-se os princípios da liberdade religiosa e da igualdade dos grupos confessionais, o que daria legitimidade ao pluralismo espiritual. (GIUMBELLI, 2008, p 81, 82)

Entretanto mesmo com a separação legal a Igreja continuou exercendo influências no âmbito político, “o princípio da separação é temperado pela possibilidade de 'colaboração’ entre Estado e religiões” (GIUMBELLI, 2008, p.82). No código civil de 1917 foi criado um fundamento jurídico que conferia personalidade aos coletivos/associações religiosas, o que denotava "reconhecer sua existência e ações legais em várias esferas, sem nenhuma restrição específica aos seus atos civis” (GIUMBELLI, 2008, p.82).

Uma outra crítica interessante ao Código civil é que ele não versa sobre a religião que teria a liberdade, mas sim na liberdade que desfrutaria a religião, o parâmetro era a Igreja Católica, sobre a qual não havia dúvidas de sua legitimidade religiosa. Isso poderia explicar o fato que aconteceu posteriormente, a criminalização da prática do "espiritismo", da "magia e seus “sortilégios”, assim como o exercício do “curandeirismo”, por uso indevido da medicina em suas práticas terapêuticas. Em defesa a esses ataques, os espíritas enfatizaram o “enquadramento de suas práticas à noção de 'religião”, utilizando a noção de caridade (GIUMBELLI, 2008, p.84) Doravante, o modo como as religiões de matrizes africanas se defenderam em algumas regiões do país foi reivindicando o estatuto de patrimônio cultural e o tombamento dos terreiros, uma vez que seus rituais estavam (e ainda são) questionados e vetados.

Com o movimento evangélico não foi diferente, segundo Mariano, no final da década de 1950 dirigentes católicos empreenderam esforços para dificultar a expansão protestante. 
Um exemplo, aconteceu no "início do Estado Novo, em 1939, o Departamento de Defesa da Fé implementou uma política de oposição ao protestantismo, em nome da defesa da "nação católica” (ROLIM, 1985, p. 72, 82 apud MARIANO, 2011, p. 247).

Somente com o processo de redemocratização, no último quarto do século $\mathrm{XX}$, que houve uma ascensão do pluralismo religioso e da competição religiosa, que se demonstrou com o acelerado crescimento dos pentecostais, seu ingresso na televisão e na política partidária. Mariano acrescenta a isso uma marcha acelerada de “destradicionalização religiosa, processo em que a adesão, a filiação, as crenças e as práticas religiosas tornam-se uma questão de opção pessoal consciente, voluntária e deliberada. Fenômeno que contribuiu para legitimar e dinamizar o trânsito religioso no país” (MARIANO, 2011, p. 247). Para o autor a ascensão do pentecostalismo foi um dos responsáveis pela expansão do pluralismo no Brasil,

Ao contrário do kardecismo e dos cultos afro-brasileiros, nos quais tais fenômenos são mais frequentes, o pentecostalismo tende a demandar laços exclusivos de seus adeptos. Proselitista e conversionista, ele foi fundamental para consolidar o pluralismo religioso no país, para reforçar a defesa do princípio da liberdade religiosa e de culto, do qual o pluralismo depende, para provocar a ruptura da lógica monopólica prevalecente no campo religioso, para pôr em xeque a estreita identificação entre catolicismo e nacionalidade brasileira e para dilatar enormemente a competição religiosa. Rompeu, assim, com o modelo hegemônico de relação inter-religiosa que prevaleceu no país até meados do século XX: o sincrético hierárquico. Esse modelo combinava uma "relação [de pertença religiosa] não-exclusiva com a aceitação da hegemonia institucional católica”, que tolerava as demais como satélites a seu redor, nos termos de Paul Freston. (MARIANO, 2011, p. 248)

Neste sentido, o autor continua argumentando que a redemocratização das instituições políticas e uma reorientação progressista da cúpula católica “abriram um amplo espaço para o avanço da concorrência religiosa, que na década de 1980 em diante, passou a pressionar cada vez mais a liderança católica”. Esses por sua vez, começaram a investir fortemente na televisão, visando "enfrentar a supremacia pentecostal nesse meio de comunicação", e incentivar a participação de leigos na política partidária (MARIANO, 2011, p. 249).

Uma vez que na sociedade laica brasileira há a presença forte e marcada da religião, há que se pensar em como o estado, e as instituições religiosas deveriam se portar no espaço público, uma vez que a religião não se contenta com o espaço privado. A religião, a partir do processo de secularização, se tornou uma agência entre as outras na esfera pública, mas muitas vezes a sua voz é reprimida e desconsiderada, como também é uma voz abusiva e uni 
lateral. Para isso vale observar o pensamento de William E. Connolly, quando argumenta sobre a presença de minorias visíveis e ideológicas no espaço público em um regime de pluralismo profundo multidimensional, entre essas minorias estaria a religião (CONNOLLY, 2011, p. 651, 652)

Para o autor em um regime profundo de pluralismo multidimensional, como no Brasil, os participantes das minorias levam ao espaço público suas demandas, crenças existenciais e posturas ontopolíticas. Em seguida recuam relacionalmente em suas posições por reconhecerem, sem ressentimento, a contestabilidade legitima que suas demandas/credos tem aos olhos do demais. Essa dupla entrada do pluralismo é profunda por que, de certa forma, atinge as espiritualidades e credos dos participantes, ao invés de tentar colocá-los em quarentena. Esse auto recuo é necessário para que diversos públicos possam negociar acordos de respeito mútuo em várias linhas de diferença. Seria um movimento de fala e escuta que deveria existir, na esfera pública. Há um espaço legítimo para a apresentação de demandas, assim como um espaço de contestação a essas demandas (CONNOLLY, 2011, p. 652).

Connolly destaca que esse movimento conta com um elemento espiritual (solicitação de gratidão pela existência, advindas da variedade de crenças religiosas) e também busca atenuar as ondas de arrogância, ressentimento existencial, cinismo que podem se propagar facilmente numa cultura de minoritização. Para ele a micropolítica ${ }^{3}$ é uma maneira chave para fomentar e ampliar as afinidades espirituais entre as diferenças de credo e outras identificações. É um ideal audacioso, porém urgentemente necessário para que haja esse movimento. Por que uma falha no aprofundamento e extensão da textura do pluralismo hoje significa o prolongamento de uma cultura de demonização, restrição e repressão de diversidade (CONNOLLY, 2011, 652).

O autor remonta essas atividades de minoritização atuais a um período anterior ao secularismo euro-americano onde se universalizou semi conscientemente um conjunto de temas cristão protestantes como política, vestuário, tempo, vontade, base moral, etc. Ele compara com a oposição francesa aos véus islâmicos em nome de uma neutralidade secular, que na verdade não são neutros ou seculares, são heranças cristãs que se naturalizaram e se

\footnotetext{
${ }^{3}$ Por Micropolítica o autor entende como práticas multimodais, implantação de misturas de imagem, ritmo, palavras, gestos e toques para ajudar a codificar os registros viscerais de subjetividade e intersubjetividade. Desse modo a Micropolítica encontraria ampla expressão em locais como igrejas, famílias, universidades, empresas, sindicatos, filmes, e especialmente nas ressonâncias de ida e vinda entre esses locais (CONNOLLY, 2011, p.650).
} 
infiltraram tão densamente na vida secular pública que não aparece como afronta à neutralidade secular (CONNOLLY, 2011, p.652).

Por isso Connolly acredita ser tão necessário esse movimento do pluralismo profundo multidimensional, pois esse ethos de engajamento procura manter torção entre apoiar as diversidades que já encontraram um lugar no espaço público e participar periodicamente na política do devir, até que novos movimentos disputem e desestabilizem um padrão estabelecido de diversidade enquanto procuram um lugar no espaço público de legitimidade e justiça. Assim a tarefa exigente seria de incorporar tal ethos de engajamento nas igrejas, famílias, escolas, nas práticas de consumo, mídia, educação e nas prioridades do Estado (CONNOLLY, 2011, p.652).

Esse movimento é o ideal e nem sempre acontece de fato na sociedade. Mesmo assim reconhece o lugar da religião dentro desse movimento. Que o fato de ser uma sociedade laica, como no Brasil, não significa uma ausência da religião, mas sim o convívio com a questão religiosa. Desse modo a presença do Ensino Religioso escolar é legitimada, porém a que se pensar num modo de como aplicá-lo para que se adeque ao espaço público.

\section{A escola e o lugar do Ensino Religioso}

Com base nessas breves análises, pode-se perceber como a religião sempre esteve presente na sociedade brasileira, não se restringindo a esfera privada, mas também ocupando lugares importantes na esfera pública como uma associação ao lado de vários outras; levando suas demandas e participando dos movimentos do espaço público. Nessas discussões entra a questão do Ensino Religioso (ER), uma vez que se trata do ensino do conteúdo religioso no contexto escolar laico. De um lado estão aqueles que são contrários, baseados numa concepção enviesada de laicidade, se baseando num modelo Francês, e tendo em mente um ER catequético, e do outro lado, os favoráveis, entendendo a composição pluralista e sincrética do Brasil acreditam num ER que abarque o fenômeno religioso numa perspectiva não confessional e não proselitista.

O histórico do ensino da religião no Brasil, conta com um ensino da religião católica desde a colonização do país. No período colonial do Brasil as organizações católicas, especialmente a Companhia de Jesus jesuítica, eram responsáveis pela educação, há quem 
diga que a articulação religiosa-pedagógica desenvolvida por eles podia ser chamada de sistema de ensino, uma vez que atuavam em duas frentes, "conversão e adaptação dos indígenas à cultura branca e uni religiosa” e a formação básica dos filhos dos colonos que poderiam futuramente seguir seus estudos em universidades europeias. (MOTA, 2015, p.76).

Mesmo com a Reforma Pombalina, que gerou a expulsão dos jesuítas do território colonial, o "poder da Igreja não diminuiu e continuou a manter o monopólio das instituições de ensino” (MOTA, 2015, p.77). Na Lei complementar a Constituição Imperial de 1824, no artigo 6, que arguia sobre a educação um dos deveres dos professores eram ensinar os “princípios de moral cristã e da doutrina da religião católica e apostólica romana”. (MOTA, 2015, p.79)

E assim seguiu com leves mudanças até o ano de 1996, com a redação da nova LDB. No ano 1997 houve uma alteração no artigo 33 onde fica garantido então um ER não confessional, não proselitista, garantindo a diversidade cultural e religiosa brasileira. Mesmo com a legislação deste modo, há ainda desconfiança por parte de muitos autores, que tem em mente o antigo ER católico, e argumento que o ER é inconstitucional e fere a laicidade do estado.

Para essa discussão, vale retomar o pensamento do filósofo francês Paul Ricouer, que aborda questões sobre laicidade, escola e religião para o contexto Francês, entretanto em sua abordagem pode-se achar pontos de contato com sociedade brasileira.

Primeiramente ele distingue a laicidade em duas perspectivas, a laicidade do Estado e a laicidade da sociedade civil. A primeira se caracteriza pela abstenção, separação entre Igreja e Estado, “delimitação rigorosa dos seus papéis respectivos”. Já a segunda é dinâmica, está ligada à discussão pública. "Numa sociedade pluralista, como a nossa, as opiniões, as convicções, as profissões de fé, exprimem-se e publicam-se livremente”, expressando os seus melhores argumentos. A escola se encontra numa posição intermediária, entre o Estado, enquanto serviço público e a sociedade civil, “que a investe com uma das suas funções mais importantes: a educação”. Destarte, o argumento do autor responde ao pensamento que alguns pesquisadores, diretores ou pedagogos escolares que rejeitam o ER baseados numa concepção enviesada de laicidade, que se equivaleria à laicidade do Estado, sem se dar conta das outras perspectivas (RICOEUR, 1997, p. 176, 177). 
Em sua concepção a escola tem duas grandes funções, informar e ensinar a discutir. Sobre a primeira ele argumenta que não é normal que os educandos "não tenham acesso ao seu próprio passado, ao seu próprio patrimônio cultural, o qual o comporta, além da herança grega, as origens judaica e cristã”. Destarte, Mota contribui com esse pensamento quanto argumenta que a educação é

um aspecto da vida que conjuntamente com outros, contribui para a adaptação do indivíduo ao convívio social, ou seja, pode ser entendida como um fenômeno pelo qual, individualmente ou em grupo, obtém-se conhecimentos de toda ordem e assim, busca-se desenvolver aptidões e capacidades. Portanto, a educação torna-se uma atividade plural, posto que sua formulação dependa da cultura a que o indivíduo esteja inserido (MOTA, 2015, p.74).

Nesse sentido o ER daria esse suporte, abordando sobre a religião também em caráter informativo, uma vez que é parte da história da constituição do estado brasileiro.

Sobre a segunda função, Ricoeur relaciona com a perspectiva da laicidade da sociedade civil, que envolve discussão e argumentação no espaço público. Sendo assim a escola deveria iniciar os alunos na "problemática pluralista das sociedades contemporâneas, talvez ouvindo argumentações contrárias conduzidas por pessoas competentes”. A religião faz parte do substrato cultural do país, seria papel do ER escolar então, oferecer aos alunos subsídios para o enfrentamento e defesa dessas questões no espaço público, local de discussões e argumentações. A escola seria o local de aprendizado e prática dos movimentos que ocorrem na esfera pública, sendo o ER o espaço para as discussões sobre a religião. (RICOEUR, 1997, p. 177,178)

A partir desses argumentos caberia então perguntar qual seria o fundamento epistemológico ou metodologia deveriam ser utilizados, pelos docentes, para que o ER resguarde essa laicidade. Ricoeur, Junqueira e Rodrigues, pensam que o fundamento epistemológico para o ER deveria estar baseado na fenomenologia da religião, pois "trata-se de conferir ao fenômeno religioso o status de matéria relevante à formação do cidadão por meio de um tipo de conhecimento que poderá contribuir à construção de sua identidade” (RODRIGUES, 2012, p.170), seria uma proposta que tem “como principal característica à mudança do campo religioso para o secular do Ensino Religioso, dando um caráter científico, epistemológico, destituído de proselitismo” (JUNQUEIRA, TEÓFILO, 2012, p.96).

Destarte, Pieper, autor que articula com as ideias de Ricouer, diz que "toda a dificuldade do tema do ER em escolas públicas existe em razão do lugar em que ela se insere: 
na encruzilhada entre Estado e Sociedade”, sendo assim, para o autor, na abordagem fenomenológica-hermenêutica há indícios para evitar duas modalidades de ER extremas: eliminação do debate sobre religião na escola ou "afirmações proselitistas da religião num espaço laico” (PIEPER, 2014, p. 144).

Em alguns estados está explicitado na lei que o foco da disciplina de ER deve ser o fenômeno religioso e que o professor habilitado para lecionar a matéria é aquele formado em Ciência (s) da (s) Religião (ões) uma vez que este curso fornece os aportes teóricos baseados na fenomenologia da religião ${ }^{4}$.

O professor João Décio Passos divide o ER em três modelos, de acordo com a história do Brasil: catequético, teológico e o da Ciência da Religião, desses três o que se acomodaria na legislação atual, respeitando a laicidade escolar estatal seria o da Ciência da Religião (PASSOS, 2007, p.65). Este modelo aprovisiona "referencias teóricas e metodológicas para o estudo e o ensino da religião como disciplina autônoma e plenamente inserida nos currículos escolares” (SOARES, 2015, p.90). Além disso este modelo "lança as bases epistemológicas para o ER, deitando suas raízes e arrancando suas exigências do universo cientifico dentro do lugar comum das demais disciplinas ensinadas nas escolas” (SOARES, 2015, p. 90). Conforme Passos:

Trata-se de reconhecer, sim, a religiosidade e a religião como dados antropológicos e socioculturais que devem ser abordados no conjunto das demais disciplinas escolares por razões cognitivas e pedagógicas. O conhecimento da religião faz parte da educação geral e contribui com a formação completa do cidadão, devendo estar sob a responsabilidade dos sistemas de ensino e submetido às mesmas exigências das demais áreas de conhecimento que compõem os currículos escolares. (PASSOS, 2007, p.65)

Sabe-se que as discussões em torno da validade do ER ainda são constantes, entretanto sobre a questão da laicidade, já existem fortes argumentos, baseados, principalmente no modo como o estado brasileiro foi constituído, que há um espaço legitimo para o ER na escola. Uma vez que este não seja confessional e não proselitista e como indica na legislação ${ }^{5}$, resguardando a diversidade cultural e religiosa brasileira. Acredita-se então, que o método amplamente divulgado e praticado da fenomenologia da religião garanta essa laicidade escolar fornecendo ao discente conhecimento e gerando cidadãos mais respeitosos e tolerantes.

\footnotetext{
${ }^{4}$ Disponível em : <www.gper.com.br/biblioteca_download.php?arquivoId=147> Acessso em 03 de agosto de 2016.

${ }^{5}$ Disponível em: <http://www.planalto.gov.br/ccivil_03/leis/L9475.htm> Acesso em 03 de agosto de 2016.
} 


\section{REFERENCIAS BIBLIOGRAFICAS}

ASAD, Talal. Introduction: Thinking about Secularism. In Formations of secular. California: Stanford University Press, 2003. Pp. 01-17.

CONNOLLY, William E. Some theses about Secularism. In Cultural Antropology, Vol. 26, Issue 4, pp. 648-656, 2011.

GIUMBELLI, Emerson. A presença do religioso no espaço público: modalidades no Brasil. Religião e Sociedade, Rio de Janeiro, 28(2): 80-101, 2008.

JUNQUEIRA, Sérgio Rogério Azevedo (org.). Ensino Religioso no Brasil. Florianópolis: Insular, 2015.

JUNQUEIRA, Sérgio Rogério Azevedo. TEÓFILO, Debora Nascimento. Secularização e sua relação com o ensino religioso. Teocomunicação, Porto Alegre, v. 42, n. 1, p. 82-97, jan./jun. 2012.

MARIANO, Ricardo. Laicidade à brasileira: Católicos, pentecostais e laicos em disputa na esfera pública. Civitas, Porto Alegre, v. 11, n. 2, p. 238-258, maio-ago. 2011.

MOTA, Raimundo Márcio. O sistema brasileiro de ensino e o lugar do ensino religioso. (In.) JUNQUEIRA, Sérgio Rogério Azevedo (org.). Ensino Religioso no Brasil. Florianópolis: Insular, 2015.

ORO, Ari Pedro. A laicidade no Brasil e no Ocidente. Algumas considerações, v. 11, n. 2, Porto Alegre: Civitas, maio-ago/2011.

PASSOS, João Décio. Ensino Religioso: Construção de uma proposta. São Paulo: Paulinas, 2007.

PIEPER, Frederico. Laicidade, escola e ensino religioso. Considerações a partir de Paul Ricoeur. Revista Estudos da Religião. vol. 28. n. 2. Universidade Metodista de São Paulo, São Paulo: 2014.

PIERUCCI, Antônio Flávio. Secularização em Max Weber. Da contemporânea serventia de voltarmos a acessar aquele velho sentido. In Rev. Bras. Ci. Soc. Vol. 13 n.37 - São Paulo, Junho - 1998.

RICOEUR, Paul. A crítica e a convicção. Lisboa: Edições 70, 1997.

RODRIGUES, Elisa. A formação do Estado secular brasileiro: notas sobre a relação entre religião, laicidade e esfera pública. Horizonte, Belo Horizonte, v. 11, n. 29, p. 149-174, jan./mar. 2012. 
SOARES, Afonso Maria Ligório. Concep̧̧ões do Ensino Religioso no Brasil. (In.) JUNQUEIRA, Sérgio Rogério Azevedo (org.). Ensino Religioso no Brasil. Florianópolis: Insular, 2015. 